\title{
Origami Tabanlı Öğrenme Yaklaşımı ile Üçgenler Konusunun Öğretiminin 9. Sınıf Öğrencilerinin Başarısına Etkisi
}

\author{
The Effect of Teaching the Triangular Issue Thorugh Origami-Based Learning Approach on The \\ Success of 9th Grade Students
}

\author{
Hasan Hüseyin Aksu*
}

\begin{abstract}
In this study, an analyzed was carried out on the effect of teaching the subject of triangles with Origami based learning approach on mathematics achievement of 9th grade students. Thus in the academic year of 2018-2019, an investigation was conducted on the two groups, each of which are made up of 16 9th grade students at a Vocational High School in a district of Giresun. The subject of 'Triangular' was taught to the experimental group $(\mathrm{N}=16)$ of 16 students through origami-based learning in parallel with the constructivist teaching approach, whereas the same subject-matter was taught to the control group $(\mathrm{N}=16)$ of 16 th grade students through traditional teaching approach. Triangular Success Test (TST) developed by researchers was used in the study. The results obtained were analyzed through SPSS statistical program. In this study, Wilcox on Signed Ranks Test and Mann Whitney U-Test were used as quantities data analysis techniques. The results obtained indicated that the course activities prepared in parallel with Origami-based learning approach was very effective to remarkably increase the level of mathematics achievement of 9th grade students in a class. Thus, this approach can be used to increase students' mathematics success in the triangular issue. In this case, using the paper folding method in such field education elective courses as 'Developing Activities in Mathematics Teaching' and 'Material Design in Mathematics Teaching', students are encouraged to develop various Origami activities and use them in teaching practices.
\end{abstract}

Structured Abstract: Introduction: In the updated Mathematics teaching curriculum, it is emphasized to include activities with folding papers while calculating the sum of the interior angles, for instance, out of the activities used to improve these skills (MEB, 2017). In the study, it was aimed to reveal the effect of triangle teaching on ninth grade students' academic achievement with Origami based teaching approach. In the research, the quasi-experimental pattern was used with pre-test and post-test control group. During the process in which the relevant achievements were covered in the experimental group, the Origami activities prepared separately for each acquisition, besides traditional teaching, were made by the students.

Method: The study group is made up of 9th grade students studying at one of the Vocational and Technical Anatolian High Schools located in Bulancak district in Giresun, in the spring term of 2018-2019 academic year. The application was carried out with 9th grade students in a classroom. 32 students participated in the study. After applications in both groups, the TST was applied as a post-test. In addition, the students

\footnotetext{
* Doç. Dr., Giresun Üniversitesi, Eğitim Fakültesi, Matematik ve Fen Bilimleri Eğitimi Bölümü.

Assoc. Prof. Dr., Giresun University, Faculty of Education, Department of Mathematics and Science Education. ORCID 0000-0002-4898-6476

hhaksu74@gmail.com

Cite as/ Atıf: Aksu, H.H. (2020). Origami tabanlı öğrenme yaklaşımı ile üçgenler konusunun öğretiminin 9. sınıf öğrencilerinin başarısına etkisi. Turkish Studies - Education, 15(4), 2343-2354. https://dx.doi.org/10.47423/TurkishStudies.43628

Received/Geliş: 15 May/Mayıs 2020

Accepted/Kabul: 28 August/Ağustos 2020

Copyright (C INTAC LTD, Turkey 
who participated in Origami-based teaching practices were asked to write their opinions about the activities into their dairies. The answers for the achievement test were analyzed with SPSS 22 package program.

Findings: The study group of this study consisted of a total of 32 individuals, 16 of whom were in experimental and 16 of whom in control groups. According to the results of the Mann-Whitney U test, the median of the experimental group was found to be 27 and the median of the control group was found to be 26.5 and no statistically significant difference was observed between the groups $(U=125, p>0.05)$. Based on the finding, the preliminary information about the triangles of the experimental and control groups can be interpreted as equivalent. Based on the results of the Wilcoxon Signed Ranks test, it was observed that there was a statistically significant difference between the pre-test and post-test scores of the 16 students who participated in the geometry teaching activities with origami. $-3,464, \mathrm{p}<0.05)$. The fact that the different result is in favor of positive sequences shows that Origami activities have a significant effect on geometry success. According to the results of the Wilcoxon Signed Ranks test, it was observed that there was a statistically significant difference between the pre-test and post-test scores of 16 students who had triangular teaching with the help of traditional teaching methods $\mathrm{z}=-1.993, \mathrm{p}<0.05)$. The fact that the different result is in favor of positive sequences shows that triangular teaching using traditional teaching methods has a significant effect on geometry success. Based on the results 16 in the control group and 16 in the experimental group, a statistically significant difference was found in favor of the experimental group between the median of the experimental group 67 and the median of the control group $46(U=58, p<0.05)$. In parallel with the finding, it can be concluded that Origami activities and triangle teaching are more effective in increasing geometry success compared to traditional methods. If the data obtained from the students' views were examined, the students stated that Origami is not only a paper folding method but also a way of learning mathematics. They also stated that they learned the concepts in a fun and lasting way through these activities.

Results: As a result of the study, it can be said that both approaches in the experimental procedures lead to a significant increase in the post-test achievement of students compared to their pre-test scores. On the other hand, according to the last test scores of the research Origami based triangle teaching was more effective on student achievement than traditional methods and a statistically significant difference was observed in favor of the experimental group $(\mathrm{U}=58, \mathrm{p}<0.05)$. According to the findings obtained from the study, it can be said that triangular teaching and Origami based teaching applications increase student achievement. This finding is very similar to the results of many studies that teach mathematics with Origami applications (Akan, 2008; Arici, 2012; Beekeeper \& Lion-Tutak, 2015; Cakmak, 2009; Dagdelen, 2012; Kandil, 2016; Kavici, 2005; Koyulhisar, 2012; Ozcelik, 2014; Simsek, 2012; Takicak, 2012). In the study, if the findings obtained from the student diaries are examined, the students stated that they were teaching the course in a more enjoyable and entertaining way with Origami applications. In the study of Pope (2002), the students stated that the course was fun in small group studies conducted with Origami activities. The results of these studies support the findings of the study. The teaching of many gains can be performed in the curriculum by creating fragmented Origami models with the paper folding method (Hacisalihoglu Karadeniz, 2017a). "With Paper Folding Mathematical Methods" course was carried out as an elective course in mathematics education program at Education Faculties at some universities in Turkey including 2018-2019 academic year education.

Keywords: Mathematics Achievement, Origami-Based Learning (NTS), Ninth Grade Students, Geometry and Measurement, Triangles

Öz: Bu çalışma, Origami tabanlı öğrenme yaklaşımı ile üçgenler konusunun öğretiminin 9. sınıf öğrencilerinin matematik başarısına etkisini belirlemek için gerçekleştirilmiştir. Bu amaçla, 2018-2019 eğitim öğretim yılında Giresun'un ilçesinde yer alan bir meslek lisesinin 9. sınıf öğrencilerinden 16'şar kişilik iki grup üzerinde araştırma yürütülmüştür. $\mathrm{Bu}$ sınıflarda "Üçgenler" konusunda deney $(\mathrm{N}=16)$ grubunda yapılandırmacı yaklaşıma dayalı Origami tabanlı öğrenme, kontrol grubunda ise $(\mathrm{N}=16)$ ise geleneksel yaklaşıma dayalı anlatım yöntemi ile ders gerçekleştirilmiştir. Araştırmada araştırmacı tarafından geliştirilen Üçgen başarı testi (ÜBT) uygulanmıştır. Elde edilen veriler SPSS 24 istatistik programı kullanılarak çözümlenmiştir. Çalışmada nicel veri analizi benimsenmiş ve parametrik olmayan testlerden Mann Whitney U-Testi ve Wilcoxon İşaretli Sıra Sayıları Testi kullanılmıştır. Çalışma sonucunda, OTÖ (Origami Tabanlı Öğrenme) yaklaşımına göre ders gerçekleştiren deney grubunda öğrencilerin matematik başarılarının, geleneksel yöntemine göre ders gerçekleştiren kontrol grubundaki öğrencilerin başarılarından.05 anlamlılık düzeyinde istatistiksel olarak daha yüksek olduğu tespit edilmiştir. Ulaşılan sonuçlar ışı̆̆ında, Origami tabanlı öğrenme yaklaşımı kullanılarak

Turkish Studies - Education, 15(4) 
hazırlanan etkinliklerin 9. sınıf öğrencilerinin matematik dersindeki başarılarını arttırmada etkili olduğu ve bu yaklaşımın öğrencilerin üçgenler konusuna ilişkin matematik başarısını arttırmada kullanılabileceğini söylemek mümkündür. "Kâğıt Katlama Yöntemi ile Matematik” dersi 2018-2019 eğitim-öğretim yılı da dahil olmak üzere Türkiye'deki bazı üniversitelerin eğitim fakültelerinin matematik öğretmenliği programında seçmeli bir ders olarak yürütülmüştür. Bu durumda "Matematik Öğretiminde Etkinlik Geliştirme" ve "Matematik Öğretiminde Materyal Tasarımı" gibi alan eğitimi seçmeli derslerinde kâğıt katlama yöntemi kullanılarak, adayların çeşitli Origami etkinliği geliştirmeleri ve bunları öğretim uygulamalarında kullanmaları yoluna gidilebilir.

Anahtar Kelimeler: Matematik Başarısı, Origami Tabanlı Öğrenme (OTÖ), Dokuzuncu Sınıf Öğrencileri, Geometri ve Ölçme, Üçgenler

\section{Giriş}

Amerika'daki Ulusal Matematik Öğretmenleri Birliği (NCTM, 2000) geometrinin, öğrencilerin ispatlama, görsel farkında olma ve matematiksel-mantıksal düşünebilme becerilerinin geliştirilmesinde önemli bir role sahip olduğunu belirtmiştir (Duatepe-Paksu \& Ubuz, 2004). Güncellenen matematik öğretim programında, bu becerilerin geliştirilmesinde kullanılacak etkinliklerden örneğin; iç açıların ölçüleri toplamı bulunurken kâğıt katlama ile yapılacak etkinliklere yer verilmesine dikkat çekilmiştir (MEB, 2017). Öte yandan bilinçli zihinsel etkinlik tarafindan yönlendirilen eşgüdümlü kas etkinliklerinden olan kâğıt katlama ve kesme, keman çalma, bitişik eğik yazı yazma, top atma, resim yapma gibi beceriler devinişsel becerilerdendir (MEB, 2007). Bu bağlamda öğrencilerin devinişsel becerilerini geliştiren, buluş yoluyla öğrenmelerini sağlayan Krigami (kâğıt kesme) ve Origami (kâğıt katlama) faaliyetleri için makas ve kâğıt kullanarak matematiği somut hale getiren günlük yaşamla ilişkisini kurabilecekleri malzemelere ihtiyaç vardır (Gür ve Kobak-Demir, 2016).

Kâğıt katlama yöntemi kullanılarak oluşturulan Origami çeşitleri: "Klasik Origami" ve "Parçalı Origami (modüler origami)" olmak üzere sınıflandırılmaktadır. Klasik Origamide tek parça kâğıttan çeşitli eşya veya hayvan figürleri yapılmaktadır. Parçalı Origami ya da modüler origami de ise birbirine denk parçalar birleştirilerek üç boyutlu geometrik cisim modeller meydana getirimektedir (Tuğrul \& Kavici, 2002). Origami türlerinden klasik ve parçalı Origami günümüzde modern origami olarak adlandırılarak yapıştırma ve kesme serbest bırakılmış; mimari Origami, popup Origami, Krigami olarak sınıflandırılmıştır (Tuğrul \& Kavici, 2002; URL-1). Bilinen Origami kâğıt katlama faaliyeti, tek bir kâğıdın yapıştırıcı ve makas kullanılmadan katlanmasının yanı sıra birden çok kâğıdın katlanarak birbirinin aynısı olan parçaların birbirine geçirilmesiyle de oluşturulabilmektedir (Arslan vd, 2013). Kâğıtları katlayarak elde edilen Origami modelleriyle matematik ile geometri arasındaki ilişkinin basitçe gösteriminden yararlanarak ortaya çıkan matematiksel ilişkiler görülebilir (Hsiao, 2015).

Literatür incelendiğinde, Origami ile matematik öğretiminin ilköğretim yıllarından daha önce de kullanılabileceğini göstermektedir. Çocukların şekillerin büyüklüklerini karşılaştırma becerilerini geliştirmede etkili olduğu belirlenmiştir (Yuzawa \& Bart, 2002). Diğer yandan Origami etkinliklerinin okul öncesi dönem çocuklarda uzamsal görselleştirme becerisi üzerinde etkili olurken bilişsel çevirme becerisi üzerinde ise harhangi bir tesirinin olmadığı da tespit edilmiştir (Kaplan, 2016). Origami ile geometri öğretiminde öğrencilerin; başarı ve tutumlarına (Şimşek, 2012), simetri başarılarına ve dörtgenler konusundaki yeterliliklerine (Dağdelen, 2012), üçgenler konusunda başarısına (Takıcak, 2012), üçgenler konusunda uzamsal görselleştirme, akıl yürütme ve geometri başarısına (Arıcı, 2012), özdeşlikleri modelleme becerilerine (Dündar, 2012), geometri başarısına (Özçelik, 2014) etkisini araştırmışlardır. Bununla birlikte Origami tabanlı matematik öğretimi uygulamalarının yaratıcılık, matematiksel düşünme, problem çözme ve akıl yürütme becerilerinin gelişimini sağladığı açığa çıkmıştır (Hacısalihoğlu Karadeniz, 2018). 
Origami etkinliklerinin ve soru sorma temelli öğretimin, öğrencilerin geometri dersine yönelik tutumlarına ile öz-yeterlik algılarına (Kandil, 2016) ve uzamsal yetenekleri üzerine (Çakmak, 2009; Işıksal \& Koç, 2014) olumlu etkisi olduğu tespit edilmiştir. Origami tabanlı öğretimin öğrencilerde iki ve üç boyutlu düşünmeleri üzerine olumlu etkilerinin olduğunu ortaya koyan çalışmalar da mevcuttur (Kurt, 2012). Origami tabanlı öğretimin öğrencilerin uzamsal düşünme (Çakmak, 2009), yüzey alanını kâğıdın boyutları yoluyla hesaplama (Wares, 2013) becerileri kazandırmada da etkili bir yöntem olduğu belirlenmiştir. Akayuure vd (2016), çalışmalarında Origami tabanlı öğretimin, öğretmenlerin geometri bilgileri üzerine etkisine göre uygulamanın mekânsal eğilim ve geometrik bilgi üzerine manidar bir tesir yaptığı, fakat mekânsal görselleştirme üzerine bir etkisinin olmadığını açığa çıkarmışlardır. Arslan (2012) çalışmasında, matematik eğitiminde Origaminin kullanılmasına yönelik ortaokul matematik öğretmen adaylarının inanç ve öz yeterlik algılarının yüksek olduğunu ortaya koymuştur.

Currier (2015)'de, Origaminin, matematiksel kavramları öğretmede ve problem çözmede kullanılmasının yararlarından söz ederek tüm sınıf düzeylerinde kullanılabilecek bir yöntem olduğuna vurgu yapmıştır. Buradan hareketle Origami tabanlı matematik ve geometri öğretimi ile ilgili çalışmaların; öğretmen, öğretmen adayları, okul öncesi dönem çocukları ve ilköğretim düzeyindeki öğrencilerle yapıldığ 1 , orta öğretim öğrencileriyle yapılan herhangi bir çalışmaya rastlanmamış olması bu çalışmanın yapılma ihtiyacını gündeme getirmiştir. Öte yandan 2015 yılında yapılan PİSA (Uluslararası Öğrenci Değerlendirme Programı) sınavının matematik okuryazarlığı bölümünde Türkiye, hem OECD (Ekonomik Kalkınma ve İşbirliği Örgütü) ülkelerinden, hem de sınava katılan tüm ülkelerden daha düşük puan almıştır (MEB, 2015). Bu durumdan yola çıkarak Milli Eğitim Bakanlığı, 2018 yılında tüm sınıf düzeylerindeki öğretim programlarını güncellemiş, ortaöğretim ve üniversitelere öğrenci seçiminde yapılan sınav sorularında da değişiklikler yapmıştır. Yüksek Öğretim Kurumları (YKS) sınavında sorulan geometri soruları, günlük hayattan örnekler içeren şekilden parça kesilmesi veya şeklin katlanmasını içeren sorular sorulmaya başlanmıştır. YKS'nin2018 yılında yaptığı “Temel Yeterlilik Testi-TYT”nde bu yönde sorulan birkaç soruya aşağıda yer verilmiştir (ÖSYM, 2018, 2019). Bu bağlamda öğrencilere bir kâğıt parçasını katlayarak ortaya çıkan geometrik şekillerin özelliklerini görmeleri sağlanabilir, kâğıt katlamayla elde edilen problemleri anlamaları ve çözmeleri beklenebilir (Hsiao, 2015). Buradan hareketle; Şekil 1'de "Temel Yeterlilik Testi-TYT"nde yer alan soruların bir kısmında bu bulgunun izlerine rastlandığ 1 söylenebilir.
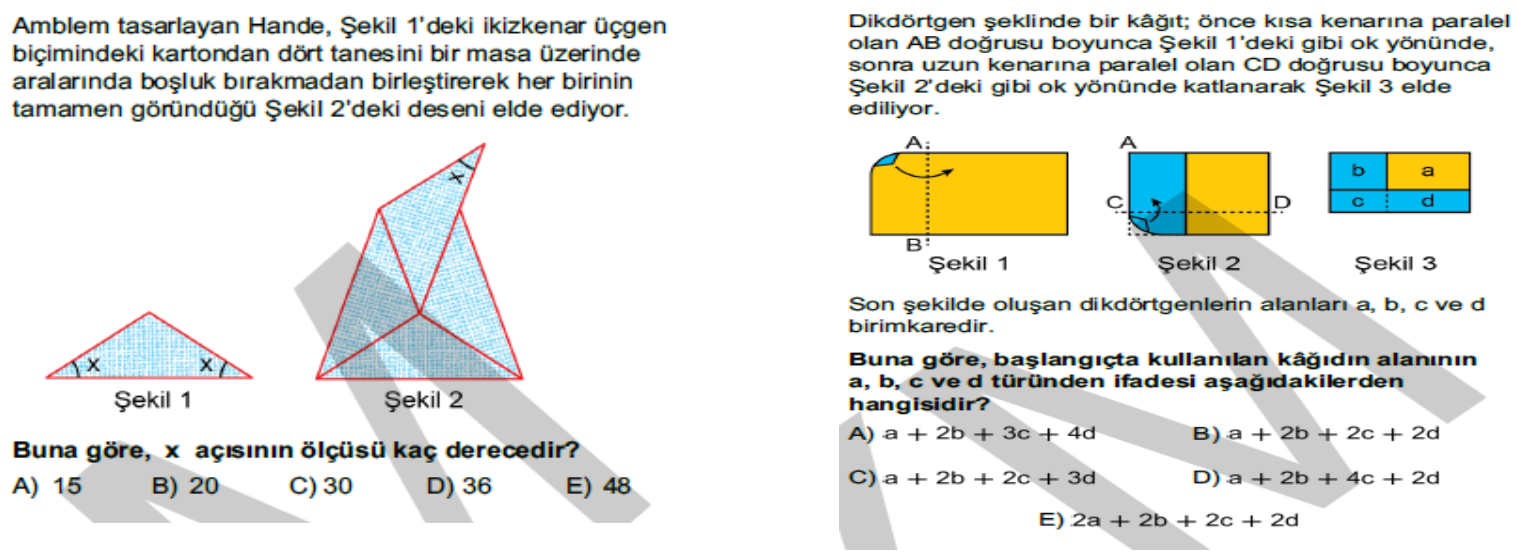

Şekil 1. 2018 Temel Yeterlilik Testinde Sorulan Bazı Geometri Soruları.

Öte yandan kâğıt katlama yöntemi kullanılarak elde edilen Origamilerin; "Sayılar ve İşlemler", "Cebir ve Olasılık" ve "Geometri ve Ölçme” öğrenme alanlarının öğretiminde kullanıldığı 
bilinmektedir (Akan-Sağsöz, 2008; Akayuure vd, 2016; Hacısalihoğlu Karadeniz, 2017, 2018; Higginson \& Colgan, 2001). Bunlardan en çok öne çıkan ve literatürde sıklıkla ele alınan öğrenme alanının, doğası gereği "Geometri ve Ölçme" öğrenme alanı olduğu söylenebilir. Dolayısıyla mevcut çalışmada, "Geometri ve Ölçme" öğrenme alanının "Üçgenler" alt öğrenme alanındaki kazanımlara odaklanılmıştır. Bu açıklamalardan yola çıkarak bu çalışmanın problem cümlesi, "Origami tabanlı üçgen öğretiminin dokuzuncu sınıf öğrencilerinin başarısına etkisi nedir?” olarak tespit edilmiştir. Söz konusu probleme yönelik aşağıdaki alt problemler oluşturulmuştur:

1. Origami etkinlikleri yapılan ve yapılmayan grubun öntest puanları arasında istatistiki açıdan manidar bir fark var mıdır?

2. Origami etkinlikleri ile üçgen öğretimi yapılan grubun öntest ve sontest puanları arasında istatistiki açıdan manidar bir fark var mıdır?

3. Origami etkinlikleri yapılmayan grubun öntest ve sontest puanları arasında istatistiki olarak manidar bir fark var midır?

4. Origami etkinlikleri yapılan ve yapılmayan grubun sontest puanları arasında istatistiki açıdan manidar bir fark var mıdır?

\section{Yöntem}

\section{Araştırmanın Deseni}

Araştırmada öntest-sontest kontrol gruplu yarı deneysel araştırma deseni benimsenmiştir. Deney grubuna ilgili kazanımların işlendiği süreç boyunca geleneksel öğretimin yanında her kazanım için ayrı ayrı hazırlanan Origami etkinlikleri öğrencilere yaptırılmıştır. Kontrol grubuna ise geleneksel öğretim yöntemi gerçekleştirilmeye devam edilmiştir. Deney ve kontrol gruplarına uygulamanın öncesinde ve sonrasında başarı testleri uygulanmıştır. Ayrıca öğrencilerin yapılan çalışmalarla ilgili düşüncelerini belirlemek amacıyla öğrencilerden Origami etkinliklerinin ardından görüşlerini yazmaları istenmiştir. Aşağıda Tablo 1'de araştırma desenine ait bilgiler sunulmuştur.

Tablo 1. Araştırmanın Deseni.

\begin{tabular}{cccc}
\hline Gruplar & Ön test & Uygulama & Son test \\
\hline Deney & Başarı testi & Origami etkinlikleri & Başarı testi \\
Kontrol & Başarı testi & $\begin{array}{c}\text { Geleneksel öğretim } \\
\text { yöntemleri }\end{array}$ & Başarı testi \\
\hline
\end{tabular}

\section{Çalıșma Grubu}

Çalışma grubunu 2018-2019 eğitim-öğretim y1lı bahar döneminde Giresun ilinin Bulancak ilçesinde yer alan bir Mesleki ve Teknik Anadolu Lisesi'nin dokuzuncu sınıfinda öğrenim görmekte olan öğrenciler oluşturmuştur. Uygulama, dokuzuncu sınıfta öğrenim gören bir şubedeki öğrencilerle gerçekleştirilmiştir. Çalışmaya 32 öğrenci katılmıştır (16's1 deney, 16's1 kontrol grubundan). Deney grubu, uygulamadan önce parçalı Origami ile hobi olarak ilgilenen öğrenciler arasından seçilmiştir. Kontrol grubu da yine aynı sınıfta öğrenim görüp Origami ile ilgili herhangi bir faaliyette bulunmayan öğrencilerden oluşmaktadır.

\section{Veri Toplama Araçları}

Araştırmaya ait veriler, çalışmayı yapan araştırmacı tarafindan oluşturulan Üçgen Başarı Testi (ÜBT) aracılığıyla toplanmıştır. ÜBT'de yer alan sorular, ortaöğretim matematik dersi öğretim programı, temel yeterlilik testi matematik soruları ve PISA matematik sorularından yararlanılarak hazırlanmıştır. Toplam 7 sorudan oluşan başarı testi, matematik dersi öğretim programının üçgenler öğrenme alanında yer alan kazanımlardan 10 tanesini ölçecek sorulardan oluşmaktadır. Sorular birden fazla kazanımı ölçecek şekilde hazırlanmıştır. ÜBT'de yer alan soruların her biri için ayrıntılı olarak cevap anahtarı hazırlanmış ve bu testten öğrencinin alabileceği en yüksek puan 100 olarak belirlenmiştir. 
ÜBT'nin geçerliliğini belirlemek amacıyla uygulamadan önce iki matematik eğitimcisi ve iki tane matematik öğretmeninin görüşlerinden yararlanılmıştır. Güvenirliğini belirlemek için yapılan analiz sonucunda CronbachAlpha güvenirlik katsayısı 0,68 olarak hesaplanmıştır.

\section{Veri Toplama Süreci}

Araştırmadan il olarak deney ve kontrol grubu öğrencilerine ÜBT öntest olarak gruplara uygulanmış ve aralarında manidar fark olmadığı görülmüştür. Araştırmanın deney grubunu oluşturan öğrenciler, çalışmadan önce de kâğıt katlama ve Origami hakkında bilgi sahibiydiler. Bu öğrenciler, Origami tabanlı öğretimin matematik eğitiminde kullanıldığını ve ne işe yaradığını bilmeden klasik ve parçalı Origami ile çeşitli figürler yapmaktaydılar. Deney grubundaki öğrencilere Giresun Üniversitesi’nde Ortaokul Matematik Öğretmenliği anabilim dalında öğrenimine devam eden ve "Kâğıt Katlama Yöntemi ile Matematik" dersini alan 3. sınıf öğrencileri ve araştırmacılardan biri tarafindan 2 hafta, her hafta ikişer saat olmak üzere toplam 4 saat boyunca klasik Origami ile geometri öğretimi yapılmıştır. Uygulamalar yapılırken 9.sınıf matematik dersi öğretim programında "Geometri ve Ölçme" öğrenme alanının "Üçgenler" alt öğrenme alanında yer alan 10 kazanım seçilmiş ve her kazanıma uygun Origami etkinlikleri hazırlanmıştır. Her Origami etkinliğinin ardından hazırlanan çalışma yapraklarıyla konunun pekiştirilmesi sağlanmıştır. Kontrol grubunda ise dersler araştırmacı tarafindan sunuş stratejisi, anlatım yöntemi, soru-cevap yöntemi ve gösteri yöntemi gibi yöntemler kullanılarak öğretmen merkezli olarak işlenmiştir. Her iki gruptaki uygulamalar bitince ÜBT son test olarak uygulanmıştır. Ayrıca Origami tabanlı öğretim uygulamalarına katılan öğrencilerden yapılan etkinliklerle ilgili görüşlerini günlüklerine yazmaları istenmiştir.

\section{Veri Analizi}

Başarı testine verilen cevaplar Statistical Package for the Social Sciences (SPSS) 24 paket programı yardımıyla çözümlenmiştir. Araştırmacı tarafından hazırlanmış olan Üçgenler Testi Puanlama Anahtarı kullanılarak öğrencilerin Başarı Testleri'ne verdikleri cevaplar puanlanmıştır. Başarı testlerinden elde edilen verilerin çözümlenmesi aşamasında, öğrencilerin sontest puanlarından ön test puanları çıkartılarak fark puanları oluşturulmuştur. Deney ve kontrol gruplarının erişileri arasında fark olup olmadığı parametrik olmayan testlerden Mann Whitney-U Testi ile test ile analiz edilmiştir. Deney ve kontrol gruplarının öntest ile son testleri arasındaki değişimler ise İki Bağımlı Örneklem için Wilcoxon İşaret Sıralaması Testi kullanılarak analiz edilmiştir. Bir araştırmada örneklem sayısı 30'un altındaysa verilerin normal dağılım sergilemeleri çok zayıf bir olasılıktır (Can, 2013). Bu durumdan yola çıkarak çalışmada örneklem sayıs1 16 kişi olduğundan veri analizinde parametrik olmayan testlerin kullanılması uygun görülmüştür. Sonuçların yorumlanmasında her iki grupta yer alan öğrencilerin puanları arasında anlamlı fark olup olmadığ 0,05 anlamlılık düzeyinde değerlendirilmiştir.

\section{Bulgular}

\section{Birinci Alt Probleme İlişsin Bulgular ve Yorum}

Çalışmanın birinci alt problemi "Origami etkinlikleri yapılan ve yapılmayan grubun öntest puanları arasında istatistiki olarak manidar bir fark var mıdır?" şeklinde belirlenmiştir. Bu alt problemi yanıtlamak üzere Mann-Whitney-U testinden faydalanılmış, elde edilen bulgular aşağıda Tablo 2'de verilmiştir.

Tablo 2. Deney ve Kontrol Gruplarının Ön Test Puanlarının Karşılaştııılmasına Ait MannWhitney-U Testi Sonuçları

\begin{tabular}{rccccc}
\multicolumn{7}{c}{ Grup } & $\mathrm{N}$ & Sıra ortalamas1 & Sıralar toplamı & $\mathrm{U}$ & $\mathrm{p}$ \\
\hline Deney grubu & 16 & 16,69 & 267 & 125 & \multirow{2}{*}{0,910} \\
Kontrol grubu & 16 & 16,31 & 261 & & \\
\hline
\end{tabular}


Deney grubunda 16 ve kontrol grubunda 16 olmak üzere toplam 32 kişilik grupta, deney ve kontrol gruplarının öntest puanları arasında anlamlı bir fark olup olmadığını ortaya koymak için yapılan Mann-Whitney U testinin sonucuna göre, deney grubunun ortancas1 27 ve kontrol grubunun ortancası 26,5 arasında istatistiki olarak manidar bir fark gözlemlenmemiştir $(U=125, p>0,05)$. Bu bulguya göre deney ve kontrol gruplarının üçgenlerle ilgili ön bilgileri denktir şeklinde yorumlanabilir.

\section{İkinci Alt Probleme İlişkin Bulgular ve Yorum}

Çalışmanın ikinci alt problemi "Origami etkinlikleri ile üçgen öğretimi yapılan grubun öntest ve sontest puanları arasında istatistiki olarak manidar bir fark var mıdır?" şeklinde oluşturulmuştur. $\mathrm{Bu}$ alt problemi yanıtlamak üzere Wilcoxon İşaretli Sıralar testinden faydalanılmış, elde edilen bulgular aşağıdaki Tablo 3'de gösterilmiştir.

Tablo 3. Deney Grubunun Ön Test ve Son Test Puanlarının Karşılaştırılmasına Ait Wilcoxon İşaretli Sıralar Testi Sonuçları

\begin{tabular}{lccccc}
\hline $\begin{array}{l}\text { Bitiş-başlangıç } \\
\text { ölçümü }\end{array}$ & $\mathrm{N}$ & Sira ortalaması & Siralar toplamı & $\mathrm{z}$ & $\mathrm{p}$ \\
\hline Negatif sıralar & 1 & 1 & 1 & $-3,464$ & 0,001 \\
Pozitif sıralar & 15 & 9 & 135 & & \\
Eşit & 0 & & & & \\
\hline
\end{tabular}

"Negatif siralar temeline dayalı.

Origami ile geometri öğretimi etkinliklerine katılan 16 öğrencinin etkinlik öncesi ve sonrasında uygulanan başarı testinden aldıkları puanlar arasında fark olup olmadığını ortaya koymak için yapılan Wilcoxon İşaretli Sıralar testinin sonucuna göre etkinliğe katılan öğrencilerin ön test ve son test puanları arasında istatistiki olarak manidar bir fark gözlenmiştir $(\mathrm{z}=-3,464, \mathrm{p}<0,05)$. Fark sonucunun pozitif sıralar lehine olması, Origami etkinliklerinin geometri başarısı üzerinde anlamlı etkisinin olduğunu göstermektedir.

\section{Üçüncü Alt Probleme İlişkin Bulgular ve Yorum}

Çalışmanın üçüncü alt problemi "Origami etkinlikleri yapılmayan grubun öntest ve sontest puanları arasında istatistiki olarak manidar bir fark var mıdır?" şeklinde oluşturulmuştur. Bu alt problemi yanıtlamak üzere Wilcoxon İşaretli Sıralar testinden faydalanılmış, verilerin bulguları aşağıda Tablo 4'de sunulmuştur.

Tablo 4. Kontrol Grubunun Ön Test ve Son Test Puanlarının Karşılaştırılmasını Gösteren Wilcoxon İșaretli Sıralar Testi Sonuçları

\begin{tabular}{lccccc}
\hline $\begin{array}{l}\text { Bitiş-Başlangıç } \\
\text { Ölçümü }\end{array}$ & $\mathrm{N}$ & Sıra ortalaması & Sıralar toplamı & $\mathrm{z}$ & $\mathrm{p}$ \\
\hline Negatif sıralar & 5 & 5,90 & 29,5 & $-1,993$ & 0,046 \\
Pozitif sıralar & 11 & 9,68 & 106,5 & & \\
Eşit & 0 & & & & \\
\hline
\end{tabular}

"Negatif siralar temeline dayalı.

Geleneksel öğretim yöntemleri yardımıyla üçgen öğretimi yapılan 16 öğrencinin, derslerin öncesi ve sonrasında uygulanan başarı testinden aldıkları puanlar arasında fark olup olmadığını tespit etmek için uygulanan Wilcoxon İşaretli Sıralar testinin sonucuna göre kontrol grubu öğrencilerinin öntest ve sontest puanları arasında istatistiki açıdan manidar bir fark gözlenmiştir $(\mathrm{z}=-1,993, \mathrm{p}<0,05)$. Fark sonucunun pozitif sıralar lehine olması geleneksel ögretim yöntemleri kullanılarak yapılan üçgen öğretiminin geometri başarısı üzerinde anlamlı etkisinin olduğunu göstermektedir. 


\section{Dördüncü Alt Probleme İlişkin Bulgular ve Yorum}

Çalışmaya ait dördüncü alt problem "Origami etkinlikleri yapılan ve yapılmayan grubun son test puanları arasında istatistiki olarak manidar bir fark var mıdır?" şeklinde oluşturulmuştur. Bu alt problemi yanıtlamak üzere Mann-Whitney-U testinden faydalanılmış, elde edilen bulgular Tablo 5 'te verilmiştir.

Tablo 5. Deney ve Kontrol Gruplarının Son Test Puanlarının Karşılaştırılmasını Gösteren Mann-Whitney-U Testi Sonuçları

\begin{tabular}{llrcrr}
\hline \multicolumn{1}{c}{ Grup } & N & Sira ortalamas1 & Siralar toplam1 & U & p \\
\hline Deney grubu & 16 & 20,88 & 334 & & 0,007 \\
Kontrol grubu & 16 & 12,13 & 194 & 58 & 0 \\
\hline
\end{tabular}

Deney grubunda 16 ve kontrol grubunda 16 olmak üzere toplam 32 kişilik grupta, her iki grubun sontest puanları arasında anlamlı bir fark olup olmadığını tespit edebilmek için yapılan MannWhitney U testinin sonucuna göre, deney grubunun ortancas1 67 ve kontrol grubunun ortancas 146 arasında deney grubu lehine istatistiki olarak manidar bir fark gözlemlenmiştir $(U=58, p<0,05)$. Bu bulguya göre Origami etkinlikleri ile üçgen öğretiminin geleneksel yöntemlere nazaran geometri başarısının artmasında daha etkili olduğu yorumu yapılabilir.

Origami etkinliklerine katılan deney grubu öğrencilerinin, yapılan etkinliklere yönelik yazdıkları görüşlerden bazı alıntılara aşağıda yer verilmiştir:

Ö7.”

“Origaminin sadece kâğıt katlama yöntemi değil matematiğin kendisi olduğunu gördüm...

"Üçgenin iç açılarının toplamının neden 180 derece olduğunu orada kâğıt katlayarak öğrendim. Çok ilginçti. Bana yararlı olduğunu düşünüyorum... Ö5.” Ö12."

“Bugün matematiğin zor olmadığını, eğlenceli hale getirerek anlaşılabildiğini gördüm...

"Origami gibi başka uygulamalar da sadece oyun gibi gözükse de bunlar matematiğin içindedir... Ö1."

“Bugün matematiğin aslında karmaşık değil eğlenceli olduğunu gördüm... Ö13.”

"Üçgenin açıortayını, kenarortayını, yüksekliğini, denge noktasını ve daha birçok şey ögrendik.... Ö3.”

"Yaptığımız Origamilerde açıortay, kenarortay, dikme, ağırlık merkezi gibi terimleri işledik ve günün sonunda bilgili ve mutlu şekilde ayrlldik... Ö9."

Öğrenci görüşlerinden elde edilen veriler incelenecek olursa, öğrenciler Origaminin sadece kâğıt katlama yöntemi değil ayrıca matematik öğrenmenin bir yolu olduğunu dile getirmişlerdir. Ayrıca bu etkinliklerle kavramları eğlenceli ve kalıcı bir şekilde öğrendiklerini belirtmişlerdir.

\section{Sonuç ve Öneriler}

Çalışmanın sonucunda elde edilen veriler dikkate alındığında deneysel uygulamalarda yer verilen iki yaklaşımın da öğrencilerin öntest puanlarına oranla sontest başarılarında anlamlı bir öğrenme artışına yol açtığı söylenebilir. Öte yandan çalışmanın sontest puanlarına göre Origami tabanlı üçgen öğretimi geleneksel yöntemlere nazaran öğrenci başarısı üzerinde daha etkili olmuş ve deney grubu lehine istatistiki olarak manidar bir fark gözlenmiştir $(U=58, p<0,05)$.

Çalışmadan elde edilen bulgulara göre Origami tabanlı öğretim uygulamaları ile üçgen öğretiminin öğrenci başarısını artırdığı söylenebilir. Bu bulgu, Origami uygulamalarıyla matematik öğretimi yapılan pek çok çalışmanın sonuçlarıyla oldukça fazla benzerlik göstermektedir (Akan, 
2008; Arıc1, 2012; Çakmak, 2009; Dağdelen, 2012; Kandil, 2016; Kavici, 2005; Koyulhisar, 2012; Özçelik, 2014; Şimşek, 2012; Takıcak, 2012, ).

Çalışmada öğrenci günlüklerinden elde edilen bulgular incelenecek olursa öğrenciler, Origami uygulamalarıyl\&a dersin, geleneksel yöntemlere oranla daha zevkli ve daha eğlenceli bir şekilde işlendiğini dile getirmişlerdir. Pope (2002)'nin çalışmasında da Origami etkinlikleriyle gerçekleştirilen küçük grup çalışmalarında öğrenciler dersin eğlenceli bir şekilde işlendiğini belirtmişlerdir. Erktim vd. (2011), Polat (2013) ve Güney (2018)'in çalışmalarında da öğrencilerin Origami uygulamalarıyla dersin alışıldık şekilde işlenen derslerden daha eğlenceli hale geldiğini belirttikleri görülmektedir. Gelişen (2017), 9.sınıf öğrencilerine "Üçgenler" konusunda Origami ve sözsüz ispat tekniklerini kullanarak yürüttüğü çalışmasında, öğrencilerin geleneksel yaklaşıma göre dersi daha zevkli ve eğlenceli işlediklerini dile getirdiklerini ortaya koymuştur. Benzer biçimde Takıcak (2012), çalışmasında Origami uygulamalarıyla 8.sınıf "Üçgenler" konusunu işlemiş, uygulamaların ardından öğrenci başarısının arttığı ve öğrencilerin geometriye yönelik olumlu tutum geliştirdikleri yönünde bir sonuç elde etmiştir. Bu çalışmanın sonuçları da göz önüne alındığında, Takıcak'ın çalışmasında elde ettiği bulguları destekler nitelikte olduğu açıkça görülmektedir.

Brady (2008)'in çalışmasında Origami etkinlikleriyle matematik öğretimi yapmış ve araştırmanın sonucunda öğrenciler; "çok eğlendim", "çok mutlu oldum" ş̧eklinde ifadeler ile memnuniyetlerini dile getirirken, "şekil oluşturmayı öğrendim" "şekilleri öğrendim" ve "üç boyutlu cisimleri öğrendim", şeklinde derse yönelik kazanımlarını dile getirmişlerdir. Eldeki çalışmanın bulgularından hareketle öğrenciler üçgendeki kavramlarla ilgili Brady (2008)'in çalışmasındaki görüşlere benzer bir şekilde uygulamaya ilişkin fikirlerini belirtmişlerdir. Mevcut çalışmada öğrencilerin günlüklerine yansıttıklarına bakıldığında; "geometriyi keşfederek, anlayarak ögrendiklerini, matematiğin karmaşık değil ĕ̆lenceli olduğunu" "gibi düşüncelere sahip oldukları açığa çıkmıştır. Bu bağlamda çalışmanın katılımcılarından elde edilen örnek öğrenci öngörüleri de bu durumu açık bir şekilde ortaya koymuştur. Benzer biçimde Sze (2005), Gür \& Kobak-Demir (2016) ve Dündar (2012) da çalışmalarında, Origami tabanlı etkinliklerin öğrencilerin keşfederek öğrenmelerini sağladığını ifade etmişlerdir. Benzer biçimde Hacısalihoğlu Karadeniz (2018) de, Origami tabanlı öğretimin öğretmen adaylarına olumlu katkılar sağladığı, keşfederek, yaparakyaşayarak öğrendiği için bilgilerin anlamlandırılmasında ve öğrenmenin kalıcı olmasında etkili firsatlardan yararlandıkları ve kavramları somutlaştırabildikleri için de kavram öğretimi/öğrenimini kolaylaştırdığı belirlenmiştir.

Kâğıt katlama yöntemi ile parçalı Origami modelleri oluşturarak öğretim programındaki pek çok kazanımın öğretimini gerçekleştirebilir (Hacısalihoğlu Karadeniz, 2017), Origami tabanlı öğretim ile "Cebir" ve "Geometri ve Ölçme" öğrenme alanları ilişkilendirilerek öğrencilerin başarılı olmaları sağlanabilir (Gür, 2015). Bunun yanı sıra Origami etkinliklerinin kullanımı öğrencilerin bilişsel gelişimlerinin yanı sıra sosyal-duygusal alanlarının gelişimine ve matematik dersine yönelik olumlu tutum geliştirmelerine katkı sağlayabilir (Boakes, 2009). Benzer biçimde, Origami tabanlı öğretimin akademik başarının yanında öğrencinin sosyal-duygusal ve devinişsel gelişimine de olumlu katkılar sağlayacağı söylenebilir (Hacısalihoğlu Karadeniz, 2018).

“Kâğıt Katlama Yöntemi ile Matematik” dersi 2018-2019 eğitim-öğretim yılı da dâhil olmak üzere Türkiye'deki bazı üniversitelerin eğitim fakültelerinin matematik öğretmenliği programında seçmeli bir ders olarak yürütülmüştür. Ancak bu ders, 2018-2019 eğitim-öğretim yılında yenilenen İlköğretim Matematik Öğretmenliği Lisans Programında kaldırılan dersler arasında yerini almıştır. Bu durumda "Matematik Öğretiminde Etkinlik Geliştirme" ve "Matematik Öğretiminde Materyal Tasarımı" gibi alan eğitimi seçmeli derslerinde kâğıt katlama yöntemi kullanılarak, adayların çeşitli Origami etkinliği geliştirmeleri ve bunları öğretim uygulamalarında kullanmaları yoluna gidilebilir. Ayrıca Origami tabanlı etkinliklerle matematik-geometri öğretmenin sadece ilköğretim ve ortaöğretim düzeyindeki öğrencilere değil, öğretmen adaylarına ve öğretmenlere de uygulanabilecek 
etkinlikler olduğu unutulmamalıdır. Son olarak, öğrencilerin uluslararası düzeyde yapılan TIMSS ve PISA gibi sınavlarda başta problem çözme ve nesneleri canlandırma becerilerini gerektiren üç boyutlu geometri sorularını çözmede yetersiz kaldıklarını, bu sorunun ortadan kaldırılmasına ilişkin öğretmen yetiştirme programlarına Origami dersinin konulmasına işaret etmiştir (Gür, 2017). Oysa 2012 yılından bu yana bazı eğitim fakültelerinin lisans programlarında yer alan bu dersin, 2018-2019 eğitim-öğretim yılından itibaren kaldırılması YÖK tarafindan uygun görülmüsstür. Öte yandan son yıllarda ÖSYM tarafından yapılan Yükseköğretim Kurumları Sınavı (YKS) ve MEB tarafindan yapılan Lise Giriş Sınavında (LGS) Origamiyle ilgili sorular sorulması dersin kaldırılmasıyla çelişen bir durumdur. Dolayısıyla Matematik öğretmenliği lisans programından kaldırılan "Kâğıt Katlama Yöntemi ile Matematik" ya da "Origami" dersinin yeniden programa konulmasının uygun olduğu düşünülmektedir.

\section{Kaynakça}

Akan-Sağsöz, D. (2008). İlköğretim 6. sinıftaki kesirler konusunun Origami yardımıyla öğretimi. [Yayımlanmamış yüksek lisans tezi]. Atatürk Üniversitesi.

Akayuure, P.,Asiedu-Addo, S. K., \&Alebna, V. (2016). Investigating the effect of Origami instruction on pre-service teachers' spatialability and geometric knowledge for teaching. International Journal of Education in Mathematics, Science and Technology, 4(3), 198-209. https://doi.org/10.18404/ijemst.78424

Arıc1, S. (2012). The effect of Origami-based instruction on spatial visualization, geometry achievement and geometric reasoning of tenth-gradestudents [Unpublished master's thesis]. Boğaziçi University.

Arslan, O., Işıksal-Bostan, M., \& Şahin, E. (2013). The development of belief scale about using Origami in mathematics education. Hacettepe University Journal of Education, 28(2), 4457.

Baki, A. (2008). Kuramdan uygulamaya matematik eğitimi (4. Bask1). Harf Eğitim Yayınc1lı.

Boakes, N. (2008). Origami-mathematics lessons: Paper folding as a teaching tool. Mathidues, 1(1), $1-9$.

Boakes, N. (2009). Origami instruction in the middle school mathematics classroom: Its impact on spatial visualization and geometry knowledge of students. Research in Middle Level Education Online, 32(7), 1-12. https://doi.org/10.1080/19404476.2009.11462060

Brady, K. (2008). Using Paper-Folding in the Primary Years to Promote Student Engagement in Mathematical Learning Proceedings of the 31st Annual Conference of the Mathematics Education Research Group of Australasia M. Goos, R. Brown, \& K. Makar (Eds.), 77-83.

Can, A. (2013). SPSS ile bilimsel araştırma sürecinde nicel veri analizi (1.Bask1). Pegem Akademi. https://doi.org/10.14527/9786053644484

Chen, K. (2006). Math in motion: Origami math for students who are deaf and hard of hearing. Journal of Deaf Studies and Deaf Education, 11(2), 262-266. https://doi.org/10.1093/deafed/enj019

Çakmak, S. (2009). An investigation of the effect of Origami-based instruction on elementary students's spatialability in mathematic. [Yayınlanmamış yüksek lisans tezi]. Orta Doğu Teknik Üniversitesi.

Dağdelen, İ. (2012). İlköğretim geometri ögretiminde simetri kavramının origami ile modellenmesi. [Yayınlanmamış yüksek Lisans Tezi]. Ondokuz Mayıs Üniversitesi. 
Duatepe, A., Ubuz, B. (2004). Drama temelli geometri ders planının geliştirilmesi ve uygulanması. Eğitimde İyi Örnekler Konferansı'nda sunulan bildiri, Sabancı Üniversitesi.

Dündar, T. (2012). İlköğretim 8.sınıf öğrencilerinin özdeşlikleri modelleme becerilerinin incelenmesi: Origami ile modellenmesi. [Yayınlanmamış yüksek lisans tezi]. Ondokuz Mayıs Üniversitesi.

Erktin, E., Aydan, Ö. \& Balc1, N.(2011). İlköğretim matematik sınıflarında "kağıt katlama" projesi, www.yeditepe.edu.tr (Erişim Tarihi: 21.05. 2019).

Gelbal, S. \& Kelecioğlu, H. (2007). Öğretmenlerin ölçme ve değerlendirme yöntemleri hakkındaki yeterlik algıları ve karşılaştıkları sorunlar. Hacettepe Üniversitesi Eğitim Fakültesi Dergisi, 33(33). https://doi.org/10.1501/egifak_0000000101

Gelişen, A. (2017). 9. sınıfta üçgenlerin öğretiminde origami ve sözsüz ispatların kullanılması ile ilgili bir ögretim deneyi. [Yayınlanmamış yüksek lisans tezi]. Cumhuriyet Üniversitesi.

Güney, E. (2018). Ortaögretim 9. sinıf üçgenler konusunda origami yardımıyla düzenlenen etkinliklerin Vanhiele geometrik düşünme düzeylerine etkisi. [Yayınlanmamış yüksek lisans tezi].Yüzüncü Yıl Üniversitesi.

Georgeson, J. (2011). Fold in Origami and unfoldmath. Mathematics Teaching in Middle School, 16(6), 354-361.

Golan, M.,\& Jackson, P. (2010). Origametria: A program to teach geometry and to develop learning Skills using the art of [http://www.emotive.co.il/Origami/db/pdf/996_golan_article.pdf]. Erişim tarihi: 06.04.2011. https://doi.org/10.1201/b10653-45

Gür, H.,\& Kobak-Demir, M. (2016). Oyun temelli matematik öğrenme laboratuvarı projesine ilişkin öğretmen adaylarının görüşleri. Necatibey Eğitim Fakültesi Elektronik Fen ve Matematik Eğitimi Dergisi(EFMED,) 10(1), 415-438. https://doi.org/10.17522/nefefmed.33834

Hacısalihoğlu Karadeniz, M. (2017a). Reflections from the application of different type of activities: special training methods course. European Journal of Educational Research (EU-JER), 6(2), 145-156. doi: 10.12973/eu-jer.6.2.157

Hacısalihoğlu Karadeniz, M. (2017b). Mathematics teaching via paper folding method. İlköğretim Online. 16(2), 663-692. doi: 10.17051/ilkonline.2017.304726

Hacısalihoğlu Karadeniz, M. (2018). Kâğıt katlama yöntemi kullanılarak tasarlanan uygulamaların matematik eğitimindeki etkililiği. III. INES Education and Social Science Congress (ESS)'de sunulan bildiri, Alanya/ Antalya.

Higginson, W. \& Colgan, L. (2001). Algebraic thinking through Origami. Mathematics Teaching in theMiddle School, 6(6), 343-349.

Kandil, S. (2016). Origami etkinlikleri ile zenginleştirilmiş sorgulama temelli öğretimin ortaokul yedinci sını öğrencilerinin yansıma simetrisi konusundaki başarıları, geometri dersine yönelik tutumları ve geometriye yönelik öz yeterlik alglları üzerine etkisinin incelenmesi. [Yayınlanmamış yüksek lisans tezi].Ortadoğu Teknik Üniversitesi.

Kaplan, E. (2016). Origami etkinliklerinin okul öncesi öğrencilerinin uzamsal görselleştirme ve zihinsel çevirme becerilerine etkisinin incelenmesi. [Yayınlanmamış yüksek lisans tezi]. Gaziantep Üniversitesi. 
Kavici, M. (2005). Gelişimsel origami eğitim programı'nın okulöncesi dönem çocuklarının çok boyutlu gelişimlerine etkilerinin incelenmesi. [Yayınlanmamış yüksek lisans tezi]. Hacettepe Üniversitesi.

Koyulhisar, T. (2012). İlköğretim 8. sinıf öğrencilerinde özdeşlikleri modelleme becerilerinin incelenmesi: Origami ile modellenmesi. [Yayınlanmamış yüksek lisans tezi]. Ondokuz Mayıs Üniversitesi.

Milli Eğitim Bakanlığı [MEB]. (2007). Çocuk gelişimi ve eğitimi psikomotor gelişim. Mesleki Eğitim ve Gelişimin Güçlendirilmesi Projesi [MEGEP].

Milli Eğitim Bakanlığı [MEB]. (2009). İlköğretim matematik dersi (6-8. sinıflar) öğretim programı. Talim Terbiye Kurulu Başkanlığı.

Milli Eğitim Bakanlığı [MEB]. (2013). Ortaokul matematik dersi (5-8. sinıflar) ögretim programı. Talim Terbiye Kurulu Başkanlığı.

National Council of Teachers of Mathematics [NCTM]. (2000). Principles and Standards for School Mathematics. Virginia.

Özçelik, B. (2014). Altıncı sınıf matematik dersi geometri ögrrenme alanında origami etkinliklerine yer verilmesinin ögrenci başarısına etkisi. [Yayınlanmamış yüksek lisans tezi]. Gazi Üniversitesi.

Philipp, R. A. (2007). Mathematics teachers' beliefs and affect. In F. K. Lester (Ed.), Second handbook of research on mathematics teaching and learning. (pp. 257-315). Charlotte, NC: Information Age Publishing.

Polat, S. (2013). Origami ile matematik öğretimi. Mustafa Kemal Üniversitesi Sosyal Bilimler Enstitüsü Dergisi, 10 (21), 15-27.

Pope, S. (2002). The use of Origami in the teaching of geometry. British SocietyforResearchinto Learning Mathematics, 67-73.

Sze, S. (2005). Math and mindmapping: Origami construction. Niagara University. (ERIC DocumentReproduction Service No. ED490352).

Şimşek, M. (2012). Geometrik cisimler konusunun origami destekli etkinlikler ile öğretiminin başarıya etkisi. [Yayınlanmamış yüksek lisans tezi]. Ondokuz Mayıs Üniversitesi.

Takıcak, M. (2012). Origami etkilerine dayalı öğretimin ilköğretim 8. sinıf öğrencilerinin üçgenler ünitesindeki akademik başarılarına ve geometriye karşı tutumlarına etkisi.[Yayınlanmamış yüksek lisans tezi]. Kastamonu Üniversitesi.

Tuğrul, B. \& Kavici, M. (2002). Kâğıt katlama sanatı ve öğrenme. Pamukkale Üniversitesi Eğitim Fakültesi Dergisi, 1(11), 1-17.

URL-1. http://www.egelisesi.k12.tr/dosyalar/editor/file/Proje35.pdf

URL-2. http://odsgm.meb.gov.tr/test/analizler/docs/PISA/PISA2015_Ulusal_Rapor.pdf

URL3. https://dokuman.osym.gov.tr/pdfdokuman/2018/YKS/TYT_01072018.pdf

Yuzawa, M. \& Bart, W. M. (2002). Young children's learning of size comparison strategies: Effect of Origami exercises. The Journal of GeneticPsychology, 163(4), 459-478. https://doi.org/10.1080/00221320209598696 